\title{
Spatiotemporal Sensitivity Characteristics of Water Resources in Huai River Ecological-Economic Belt, China
}

\author{
Congsheng Wang, ${ }^{1,2}$ Ruyin Long, ${ }^{1}$ Guangxiong Mao, ${ }^{3}$ Lei Cao, ${ }^{3 *}$ and Wei-Ling $\mathrm{Hsu}^{3 * *}$ \\ ${ }^{1}$ School of Management, China University of Mining and Technology, \\ No. 1, Daxue Road, Xuzhou, Jiangsu 221116, China \\ ${ }^{2}$ School of Economics and Management, Huaiyin Normal University, \\ No. 111, ChangJiang West Road, Huai'an City, Jiangsu 223300, China \\ ${ }^{3}$ School of Urban and Environmental Science, Huaiyin Normal University, \\ No. 111, ChangJiang West Road, Huai'an City, Jiangsu 223300, China
}

(Received September 21, 2020; accepted February 18, 2021)

Keywords: water resources, temporal and spatial characteristics, Huai River

To achieve precision control of water resources in the Huai River Basin, the precision of the forecast and control of such resources must be improved. In the present study, a recharge method was applied to the basic data obtained from the quantitative forecast and precision control of water resources in the Huai River. In addition, the water balance method was used to analyze the spatiotemporal characteristics of the water resources in the Huai River ecological-economic belt (hereafter the eco-economic belt). Using data on water resources in the eco-economic belt from 1998 to 2018, we explored the spatiotemporal changes and the characteristics of the water resources in the region. The analysis revealed the following: (1) The eco-economic belt has abundant water resources with regard to total volume, but they are unevenly spatiotemporally distributed. (2) The water resources in the eco-economic belt display a declining trend. Abundant water resources are concentrated in the provinces of Anhui, Henan, and Jiangsu, while they are relatively scarce in Hubei. (3) Examination of the changes in the water resources of the provinces located in the eco-economic belt indicates substantial changes in total water resources and rainfall on an annual basis. Henan and Anhui had the largest and smallest annual changes in total water resources, respectively. The rainfall changes are essentially periodic; that is, they alternate annually between high and low over time. Henan and Hubei had the highest changes in surface water resources and groundwater resources, respectively. (4) Rainfall is the primary source of the water resources in the eco-economic belt. The spatial distributions of surface water and groundwater are consistent. Overall, the present study provides valuable empirical evidence of water resource control in the eco-economic belt.

\section{Introduction}

High-precision automatic sensors and sensing systems are used in the management of water resources, which is a critical global issue. Such equipment can be effectively applied in the governmental allocation of water resources. Accuracy in precipitation forecast is of great

\footnotetext{
*Corresponding author: e-mail: lc@hytc.edu.cn

${ }^{* *}$ Corresponding author: e-mail: quartback@hotmail.com

https://doi.org/10.18494/SAM.2021.3110
} 
importance to flood control and drought relief, as well as to water resource management. ${ }^{(1)}$ Drought and extreme precipitation events can have significant environmental and socioeconomic impacts. The effects of global warming and intensified anthropogenic activity (e.g., water reservoir construction, urbanization, and deforestation) are expected to accelerate the global hydrological cycle ${ }^{(2,3)}$ and thus alter the spatiotemporal patterns of precipitation. This is in turn projected to result in the increased occurrence of extreme weather events, including severe droughts or floods, in numerous regions around the globe. ${ }^{(4)}$ In 1985, the Japan Ministry of the Environment enforced a special measures law to conserve water quality in lakes. ${ }^{(5)}$ Water resources constitute a nonconventional factor that affects national security. Both the shortage of water resources per capita and the uneven regional distribution of water resources in China are expected to hinder the sustainable development of the national economy. For example, the total amount of water resources per capita in the Huai River ecological-economic belt (hereafter the eco-economic belt) is only $21.4 \%$ and $6.8 \%$ of the national and global averages, respectively. ${ }^{(6)}$ The imbalance between the supply and demand of water resources is one of the most serious problems facing this region.

Anthropogenic activities affect ecosystems through multiple routes, including land use strategies. Changes in ecological processes in turn affect ecosystem services. For example, the human destruction of forests and grassland not only results in reduced biodiversity and weakened ecosystems but also reduces soils' resistance to erosion, thereby leading to a decline in ecosystem services such as soil and water conservation. ${ }^{(7,8)}$ Surface water changes are a pivotal indicator of environmental, climatic, and anthropogenic activities. ${ }^{(9)}$ Droughts and floods have devastating impacts on regional agriculture, water resources, and the environment, with severe ecological and social consequences. ${ }^{(10)}$ The problem of regional water resources has always been the center of attention from all sectors of society. Moreover, it has received considerable scholarly attention. Numerous domestic researchers have investigated the water resources in various basins and regions. ${ }^{(1-14)}$ Deng and $\mathrm{Li},{ }^{(15)}$ Liu et al., ${ }^{(16)}$ Zhao et al., ${ }^{(17)}$ Wang et al., ${ }^{(18)}$ and Niu et al. ${ }^{(19)}$ have studied the changes in the spatiotemporal characteristics of the Huai River Basin, as well as those in its water resources and precipitation (on the basis of water resources data).

The issuance of the Development Plan of the Huai River Ecological-Economic Belt in 2018 marked the promotion of the development of the eco-economic belt to the status of a national strategy. Thus, the eco-economic belt was selected as the research area in the present study. The changes in the spatiotemporal characteristics of the water resources over time were determined according to relevant data collected from 1998 to 2018. The present findings serve as a reference for improving the mechanisms by which these resources are managed, with sustainable development as a foundation. Information on the spatiotemporal changes in the water resources will be provided in the process. The primary aims are to ensure the even distribution, efficient utilization, and effective coordination of ecological, environmental, and water resources in this region. In this context, the relationship between the water resources and economic development has a scientific basis. At the same time, the problem investigated in the present study is a microcosm of the problem of water resources in China. Thus, the present findings can also be used to inform research on the availability and use of water resources in other regions of China. 


\section{Research Area and Data Source}

\subsection{Overview of the research area}

Mountains rich in biodiversity and ecosystem services contribute considerably to economic activities, for example, through hydroelectricity generation and through tourism, agriculture, and animal husbandry. ${ }^{(20-22)}$ These essential ecosystem services also characterize regional climates. However, these ecosystems face anthropogenic pressures caused by high population growth and global warming, which further lead to changes in the hydrological cycle and the retreat of glaciers. ${ }^{(21)}$ The warming of the planet, which has been observed over the past few decades, is related to climate change. The eco-economic belt is expected to cover the main stem and main tributaries of the Huai River as well as the area flowing through the Yishusi river system in its lower reaches, an area encompassing the provinces of Jiangsu, Shandong, Anhui, and Henan, as well as some counties and cities in Hubei Province as shown in Fig. 1. The total planned area is $243000 \mathrm{~km}^{2}$. The location of the north-south climate transition zone in this area means that the eco-economic belt will be considerably affected by the East Asian monsoon, ${ }^{(18,23)}$ which is responsible for the hot, humid summer climate. During this season, temperatures are higher inland and in the south than on the coast or in the north, exhibiting extreme differences that can reach $18.6^{\circ} \mathrm{C}$. Moreover, precipitation is unevenly distributed over this area. ${ }^{(19)}$ Winter and spring bring little rainfall and are characterized by drought, whereas summer and fall are sultry and rainy. Sharp changes in temperature and dryness can be observed. ${ }^{(24)}$ The eco-economic belt is located in the transition zone between north China, which features dryness and low precipitation, and south China, which features abundant rainfall. The distribution of precipitation is uneven on both spatiotemporal and annual bases. Specifically, the north and south have less and more precipitation, respectively. Thus, the situation of "drizzle, heavy rain, and drought" occurs frequently. ${ }^{(25)}$

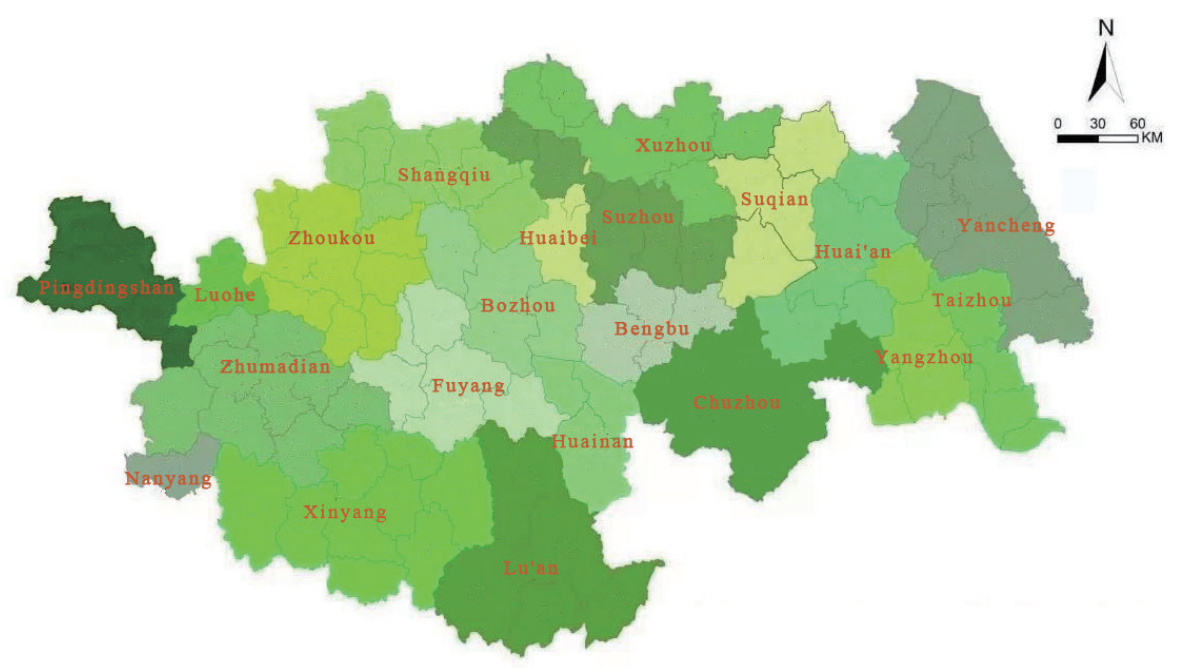

Fig. 1. (Color online) Map of the Huai River eco-economic Belt. Source: Development Plan of the Huai River Ecological-Economic Belt (2016-2030). 


\subsection{Data source}

Access to digital information is changing people's lives and the world of business, often radically. Technological developments in the future are expected to be at least as substantial as those that have been made. ${ }^{(26)}$ The progressive increase in the volume of data produced necessitates the evaluation of data quality, so that knowledge can be gleaned from subsequent processing. ${ }^{(27)}$ In this study, the quantitative forecast and precision control of water resources in the Huai River were used to improve the precision of water resource control in the Huai River Basin. A combination of online monitoring, quantitative forecast, precision control, and comprehensive decision-making was used. Research was conducted to address key problems concerning the quantitative forecast and real-time control of water resources, as well as a service support platform for comprehensive decision-making with regard to water resources. The following monitoring actions were performed for the quantitative forecast of water resources, multilevel joint control of hydraulic projects, precision control of water resources, and service support for comprehensive decision-making: ${ }^{(28)}$

(1) Multiscale and multiprocess coupling technique for the quantitative forecast of water resources

Using long-time-series and multiwave historical meteorological and hydrological data, the major control factors of the large-scale flow field stability, the runoff generation and confluence mechanism in the underlying surface, and their spatiotemporal variability characteristics were systematically analyzed. A multiscale rainfall forecast model and a serialized hydrological model with clear physical mechanisms were constructed. By using meteorological and hydrological monitoring data that were subjected to multiscale and multiprocess coupling, a downscaling technique for the meteorological data model and a scale-variant coupling method for meteorological and hydrological data were developed. A water resource quantitative forecast model that was based on multiscale and multiprocess coupling was constructed. A progressivecorrection dynamic forecast method that integrated long-term, medium-term, and short-term data was proposed, which effectively improved the precision of the quantitative forecast of water resources.

(2) Multiproject and multilevel precision control of water resources

On the basis of the evolutionary mechanisms and characteristics of basin water resources, a multilevel, joint-control conceptual network for Huai River's water resources was constructed according to the interactive relations within each unit, each region, and the basin. Realtime calculation of water resource allocation in lake reservoirs and dams was conducted by combining medium-term and long-term forecasts of the water resource supply and the forecast of water levels, which was quantitatively closer to the actual levels compared with the conventional statistics-based characteristic water level. The flexibility of the real-time control of hydraulic equipment was fully considered. Capitalizing on the advantages of optimization and simulation strategies, we developed a model for the real-time allocation of water resources (using supply-demand layered coupling). The joint control network and allocation model were integrated on the basis of the principles of node matching and region correspondence to establish a rolling correction technique. This facilitated real-time feedback to and regulation of 
the regional water resource supply and demand and the planning of water resource allocation for projects. A precision control system for basin water resources that integrated temporal factorslong-term, medium-term, and short-term data — and spatial factors - multilevel coupling — was constructed.

(3) Multi-information and multifunction support services and platform for comprehensive decision-making for water resources

Massive datasets from various sources, such as multiscale meteorological and hydrological observation, short messages from the BeiDou Navigation Satellite System, multitemporal remote sensing, and high-resolution radar observation, were integrated to establish high-density hydraulic project groups and to construct a multiscenario, full-process simulation system for water resource allocation that considered the complexity of water resource systems. A water resource message transmission system, comprising a WeChat platform, a water resource information centre, personal terminals, and multiple server terminals, was developed. Thus, we developed multi-information and multifunction (information integration, coupling, simulation, forecast, allocation, emergency response, real-time control, and effect evaluation) services and a platform for comprehensive decision-making for water resources.

On the basis of water resource data from Henan, Anhui, Jiangsu, Shandong, and Hubei, which are encompassed within the planned area of the eco-economic belt, changes in spatiotemporal characteristics of water resources in this region were examined and analyzed. The primary data source was a bulletin on water resources in the Huai River (1998-2018).

\section{Results and Discussion}

The total volume of regional water resources is the sum of the surface water and groundwater supplied from local precipitation. Specifically, it is the sum of the surface runoff (which is the difference between river runoff and river base flow) and the precipitation infiltration recharge. ${ }^{(24)}$

The total volume of water resources was calculated using the following equation:

$$
W=R_{S}+P_{r}=R+P_{r}-R_{g}
$$

where $W$ is the total volume of water resources, $R_{S}$ is the surface runoff, $P_{r}$ is the precipitation infiltration recharge, $R$ is the river runoff, and $R_{g}$ is the river discharge attributable to the precipitation infiltration recharge (the river base flow is in the hilly area). ${ }^{(25)}$

The total water resources in the study area (comprising the five provincial administrative divisions) were calculated using Eq. (1) on the basis of the data on water resources in the five provinces. The results are shown in Table 1.

\subsection{Analysis of time change characteristics}

As shown in Fig. 2, the maximum and minimum precipitation volumes were 292.4 billion and 169.504 billion $\mathrm{m}^{3}$ in 2005 and 2003, respectively, which is consistent with the characteristics of precipitation in the country. As mentioned, the eco-economic belt is located in the climate transition zone between north and south China. The effects of the East Asian 
Table 1

Data on water resources in the Huai River eco-economic belt (1998-2018).

\begin{tabular}{lcccrr}
\hline Year & $\begin{array}{c}\text { Amount of precipitation } \\
\left(10^{8} \mathrm{~m}^{3}\right)\end{array}$ & $\begin{array}{c}R \\
\left(10^{8} \mathrm{~m}^{3}\right)\end{array}$ & $\begin{array}{c}P_{r} \\
\left(10^{8} \mathrm{~m}^{3}\right)\end{array}$ & $\begin{array}{c}R_{g} \\
\left(10^{8} \mathrm{~m}^{3}\right)\end{array}$ & $\begin{array}{c}W \\
\left(10^{8} \mathrm{~m}^{3}\right)\end{array}$ \\
\hline 1998 & 2856.70 & 927.00 & 462.10 & 119.40 & 1269.70 \\
1999 & 1881.60 & 292.30 & 285.60 & 63.20 & 514.70 \\
2000 & 2745.70 & 828.90 & 458.30 & 122.50 & 1164.70 \\
2001 & 1698.80 & 288.61 & 264.68 & 70.33 & 482.96 \\
2002 & 2099.11 & 414.37 & 317.25 & 75.04 & 656.58 \\
2003 & 1695.04 & 1400.69 & 519.65 & 225.30 & 1695.04 \\
2004 & 2145.62 & 440.43 & 330.31 & 117.54 & 653.20 \\
2005 & 2924.00 & 1010.00 & 439.06 & 183.06 & 1266.00 \\
2006 & 2353.00 & 600.74 & 341.71 & 116.01 & 826.44 \\
2007 & 2722.70 & 949.60 & 410.78 & 161.48 & 1198.90 \\
2008 & 2430.00 & 670.91 & 363.35 & 128.92 & 905.34 \\
2009 & 2251.26 & 483.27 & 335.21 & 107.56 & 710.92 \\
2010 & 2343.04 & 632.60 & 353.55 & 126.56 & 859.59 \\
2011 & 2194.56 & 533.11 & 328.24 & 111.22 & 750.13 \\
2012 & 2013.29 & 452.67 & 294.94 & 98.21 & 649.40 \\
2013 & 1926.24 & 379.62 & 285.74 & 95.90 & 569.46 \\
2014 & 2274.70 & 470.98 & 315.14 & 97.39 & 688.73 \\
2015 & 2360.45 & 574.38 & 334.52 & 109.79 & 799.11 \\
2016 & 2595.41 & 705.09 & 380.70 & 130.17 & 955.62 \\
2017 & 2502.55 & 645.14 & 369.33 & 133.62 & 880.85 \\
2018 & 2536.20 & 662.05 & 360.44 & 135.48 & 887.01 \\
\hline Average & 2311.90 & 636.31 & 359.55 & 120.41 & 875.44 \\
\hline
\end{tabular}

Note: The data were sourced from a bulletin on Huai River water resources (1998-2018) and then compiled by the author.

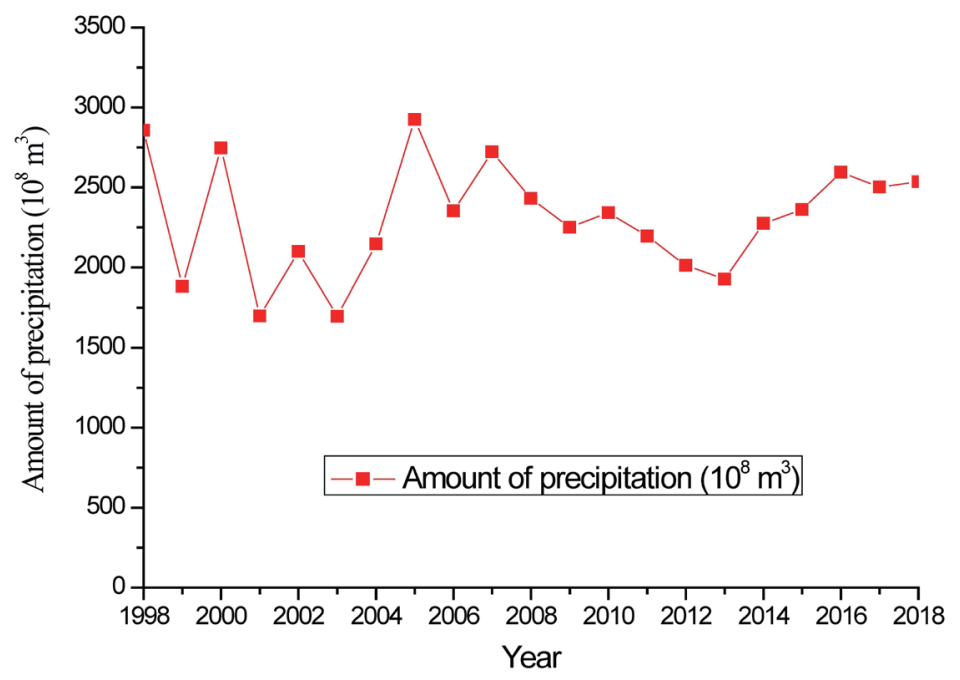

Fig. 2. Trend of changes in precipitation in the Huai River eco-economic belt (1998-2018). Note: The data were sourced from a bulletin on Huai River water resources (1998-2018) and then compiled by the author.

monsoon are primarily responsible for the uneven spatiotemporal distribution of precipitation, as indicated in the interannual variations. A certain periodicity characterized by alternation between high and low precipitation is observable. 
As shown in Fig. 3, the maximum and minimum volumes of water resources in the ecoeconomic belt over the study period were 169.504 billion and 48.296 billion $\mathrm{m}^{3}$ in 2003 and 2002, respectively. Clear interannual differences in total water resources, ascribable to numerous factors, including precipitation, are observable. Notably, the changes are greater before 2010 and the trend is relatively stable after 2010. Moreover, the total volume of water resources decreased linearly on an annual basis. Over the study period, the average volume was 87.5 billion $\mathrm{m}^{3}$. However, this amounts to only approximately $540 \mathrm{~m}^{3}$ per capita, which is only slightly higher than the amount available in regions with what is known as absolute water scarcity $\left(<500 \mathrm{~m}^{3}\right)$.

As shown in Fig. 4, the annual changes in surface water resources in the region were relatively substantial before 2010. After 2010, the changes were smaller and appeared to plateau. Overall, a linear trend of decline that is consistent with the regional trend of precipitation is observable.

As shown in Fig. 5, the groundwater resources in the eco-economic belt fluctuated before 2007. After 2007, they decreased and then increased, and then remained relatively stable. Moreover, no notable changes in groundwater resources were observed. However,

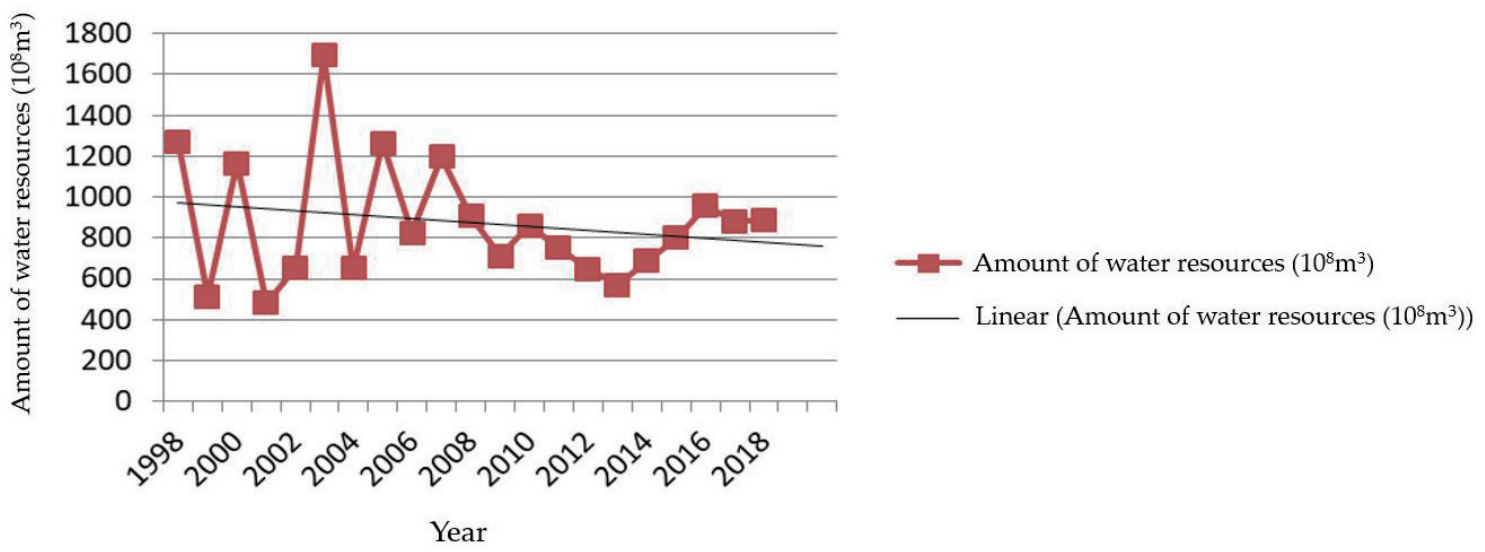

Fig. 3. (Color online) Trend of the changes in total water resources in the Huai River eco-economic belt (1998-2018).

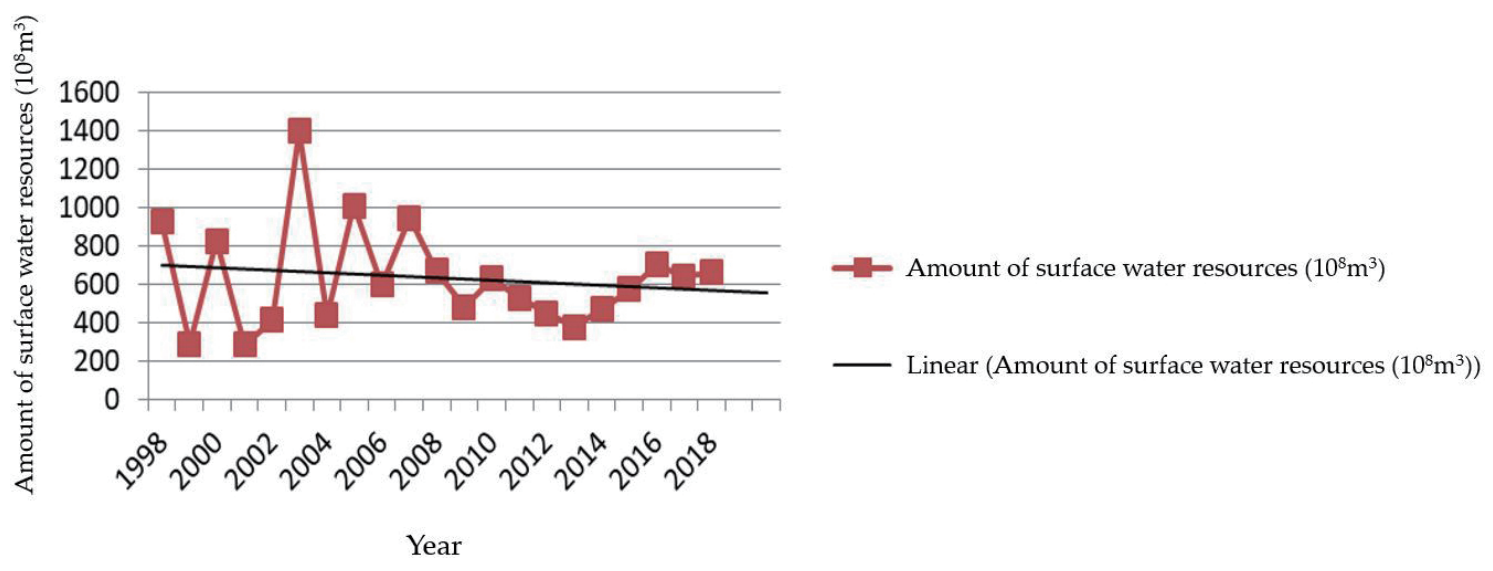

Fig. 4. (Color online) Volume of surface water resources in the study area (1998-2018). 


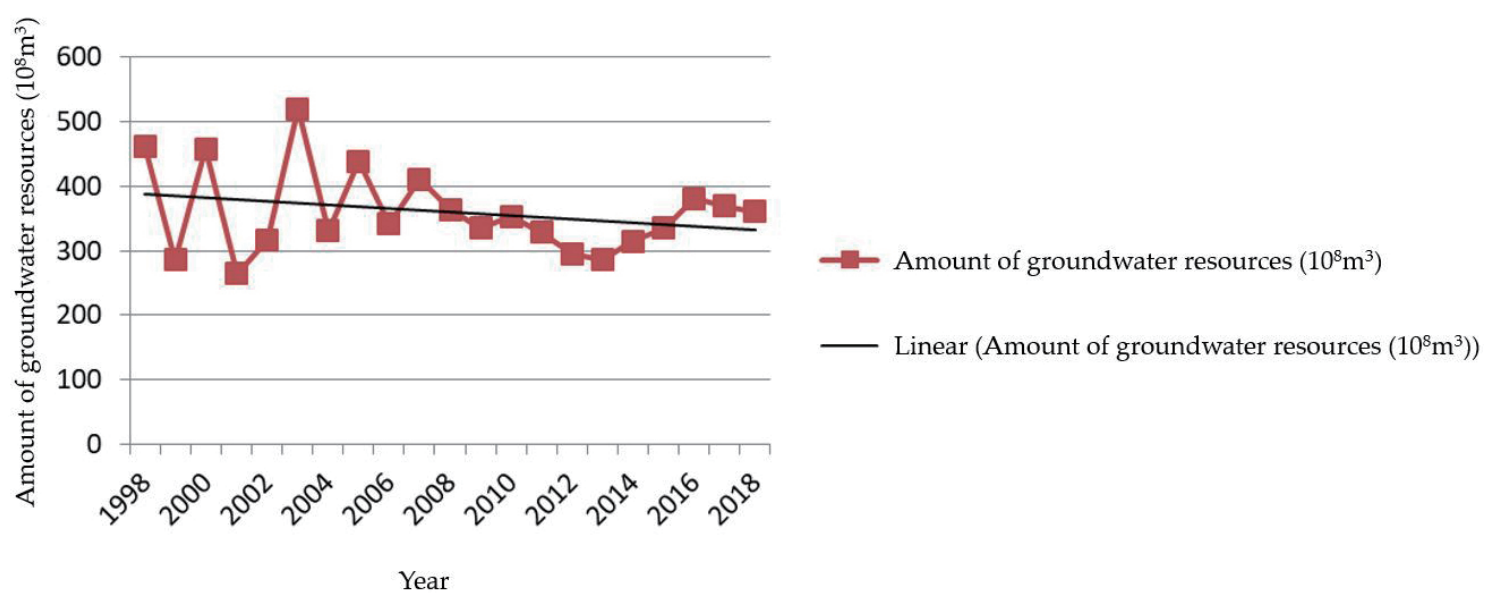

Fig. 5. (Color online) Volume of groundwater resources in the Huai River eco-economic belt (1998-2018).

because of environmental problems such as subsidence, desertification, seawater intrusion, and groundwater overexploitation, the total volume of groundwater resources in the region is relatively low, and the overall trend is declining.

The analysis revealed a strong correlation between the total volume of water resources, the total volume of surface water resources, and precipitation in the eco-economic belt, as indicated by the fact that the trend in the increase and decrease in water resources corresponds to that of precipitation. The data suggest that the quantity of groundwater resources is affected by both natural and anthropogenic factors.

\subsection{Analysis of spatial change characteristics}

In descending order, the averages of the total water resources, the groundwater resources, and precipitation of the five provinces and regions within the planning scope of the eco-economic belt from 2008 to 2018 (Table 2, Figs. 6 and 7) are as follows: Anhui (24.344 billion $\mathrm{m}^{3}$ ), Jiangsu (23.237 billion $\mathrm{m}^{3}$ ), Henan (19.342 billion $\mathrm{m}^{3}$ ), Shandong (10.629 billion $\mathrm{m}^{3}$ ), and Hubei $\left(384\right.$ million $\mathrm{m}^{3}$ ). The maximum-minimum ratio reflects the annual variation in the total water resources (Table 2). The maximum and minimum of these ratios are 4.98 and 1.88 (Henan and Anhui), respectively. In descending order, the average precipitation is as follows: Henan $\left(68.08\right.$ billion $\left.\mathrm{m}^{3}\right)$, Anhui (64.94 billion $\mathrm{m}^{3}$ ), Jiangsu (60.223 billion $\left.\mathrm{m}^{3}\right)$, Shandong (36.613 billion $\mathrm{m}^{3}$ ), and Hubei $\left(1.307\right.$ billion $\left.\mathrm{m}^{3}\right)$. The average volume of groundwater resources is consistent with the average precipitation (maximum and minimum: 10.564 billion and 85 million $\mathrm{m}^{3}$ in Henan and Hubei, respectively). Overall, the results demonstrate that the distributions of the total water resources and precipitation of the eco-economic belt have significant spatial differences. Specifically, they are higher in the south and in coastal areas and lower in the north and in inland areas. 
Table 2

Water resources of five provinces in the Huai River ecological-economic belt.

\begin{tabular}{lcccc}
\hline Province & $\begin{array}{c}\text { Average total amount of } \\
\text { water resources }\left(10^{8} \mathrm{~m}^{3}\right)\end{array}$ & $\begin{array}{c}\text { Maximum annual total } \\
\text { amount }\left(10^{8} \mathrm{~m}^{3}\right)\end{array}$ & $\begin{array}{c}\text { Minimum annual total } \\
\text { amount }\left(10^{8} \mathrm{~m}^{3}\right)\end{array}$ & $\begin{array}{c}\text { Maximum } / \text { minimum } \\
\text { ratio }\end{array}$ \\
\hline Hubei & 3.84 & 6.33 & 1.35 & 4.69 \\
Anhui & 243.44 & 333.88 & 177.27 & 1.88 \\
Henan & 193.42 & 284.53 & 57.12 & 4.98 \\
Jiangsu & 232.37 & 315.08 & 164.28 & 1.92 \\
Shangdong & 106.29 & 148.20 & 60.33 & 2.46 \\
\hline
\end{tabular}

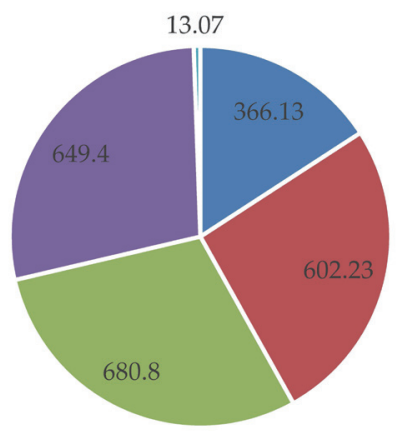

Unit: $10^{8} \mathrm{~m}^{3}$

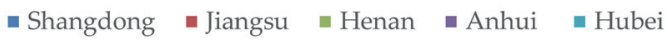

Fig. 6. (Color online) Average precipitation in five provinces in the Huai River eco-economic belt.

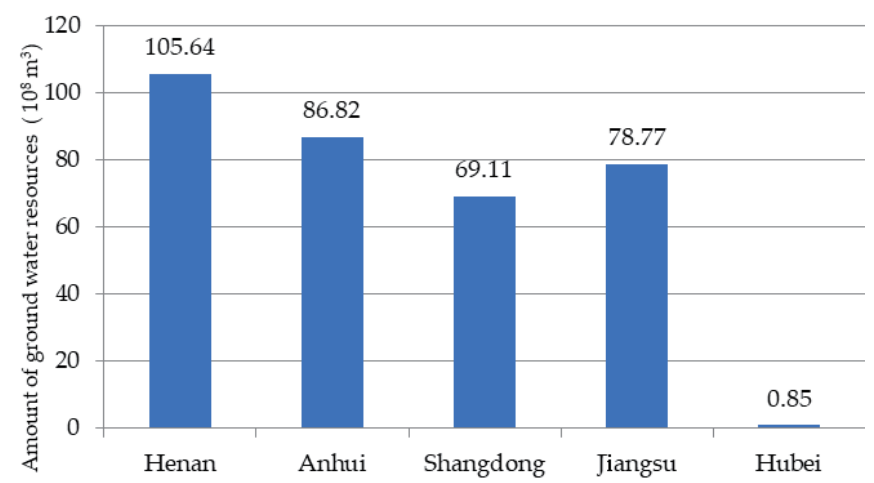

Fig. 7. (Color online) Average volume of groundwater resources in five provinces located within the Huai River eco-economic belt.

\section{Conclusions}

In this study, the spatiotemporal differences in the water resources of the eco-economic belt were examined on the basis of the data on surface water, groundwater, and total water resources in the five provincial administrative units of the Huai River eco-economic belt from 1998 to 2018 and their multiyear averages. Overall, water resources in the region were abundant but unevenly spatiotemporally distributed. Detailed conclusions are presented as follows: 
(1) The trend of the changes in water resources in the eco-economic belt is characterized by decreasing fluctuations. The annual variation of total water resources and precipitation is large and appears to be on a slow decline, and the precipitation alternates between high and low. Regarding the annual variations in total water resources, the maximum and minimum ratios were 4.98 and 1.88 in Henan and Anhui, respectively. The interannual variation in surface water resources is consistent with the fluctuation in precipitation, especially in Henan. In Hubei, the variation in groundwater resources was more significant.

(2) The water resources in the eco-economic belt are not evenly spatially distributed; they are concentrated in Anhui, Henan, and Jiangsu, while Hubei exhibits relative water scarcity.

(3) The total volume of water resources increases or decreases with the increase or decrease in annual precipitation. Overall, the trend is characterized by fluctuation and decline. The total volume of water resources is similar to the interannual variation in annual precipitation, as well as to the general trend and spatial distribution of the variation.

The present findings serve as a reference for the supply and distribution of water resources in the five provinces within the eco-economic belt. In particular, they can be used to ensure the effective allocation of regional water resources. In future studies, more advanced monitoring systems based on a network of sensors can be established in a timely manner. Moreover, the spatiotemporal sensitivity characteristics of water resources from historical records can be examined. In addition, a more accurate analysis of estimates of dynamic water resources should be performed.

\section{Acknowledgments}

The National Social Science Fund of China, grant number 18AZD014.

\section{References}

1 G. Li, X. Ma, and H. Yang: Information 9 (2018) 177. https://doi.org/10.3390/info9070177

2 Z. Zeng, W. Wu, Y. Li, Y. Zhou, Z. Zhang, S. Zhang, Y. Guo, H. Huang, and Z. Li: Water 12 (2020) 2097. https://doi.org/10.3390/w12082097

3 S. M. Vicente-Serrano, C. Azorin-Molina, A. Sanchez-Lorenzo, J. Revuelto, E. Morán-Tejeda, J. I. LópezMoreno, and F. Espejo: Water Resour. Res. 50 (2014) 8458. https://doi.org/10.1002/2014WR015427

4 P. C. D. Milly, R. T. Wetherald, K. Dunne, and T. L. Delworth: Nature 415 (2002) 514. https://schlr.cnki.net/ Detail/index/SJPD_02/SJPD12090202666811

5 M. Tani, A. Sawada, T. Oyabu, and K. Seiryo: Sens. Mater. 18 (2006) 91. https://myukk.org/SM2017/sm_pdf/ SM633.pdf

6 H. Li: China Land Resour. Econ. 28 (2015) 36. https://kns.cnki.net/KCMS/detail/detail.aspx?dbcode=CJFQ\&d bname $=$ CJFDLAST2015\&filename $=$ ZDKJ201504011\&v $=$ MTAzMTFxRnlIbVZick9QeW5BWkxHNEg5VE1 xNDIFW1ISOGVYMUx1eFITN0RoMVQzcVRyV00xRnJDVVI3cWZidWQ=

7 Z. Wang, J. Cao, C. Zhu, and H. Yang: Sustainability 12 (2020) 5707. https://doi.org/10.3390/su12145707

8 J. Wang, W. Zhou, S. T. Pickett, W. Yu, and W. Li: Sci. Total Environ. 662 (2019) 824. https://doi.org/10.1016/ j.scitotenv.2019.01.260

9 T. D. Acharya, A. Subedi, H. Huang, and D. H. Lee: Sens. Mater. 31 (2019) 1429. https://doi.org/10.18494/ SAM.2019.2264

10 T. Sternberg: Nature 472 (2011) 169. https://doi.org/10.1038/472169d

11 J. Wang, C. Li, and B. Sun: Bull. Soil Water Conserv. 37 (2017) 115. https://doi.org/10.13961/j.cnki. stbctb.2017.02.016

12 Q. Zhang, P. Sun, and X. Chen: Sci. Geog. Sin. 31 (2011) 1430. https://doi.org/10.13249/j.cnki.sgs.2011.12.003 
13 X. Zou and Y. Kong: Agric. Technol. 31 (2011) 76. https://kns.cnki.net/KCMS/detail/detail.aspx?dbcode=CJF Q\&dbname $=$ CJFD2011\&filename $=$ NYYS201102022\&v=MTY1MjV4WVM3RGgxVDNxVHJXTTFGckNVU jdxZmJ1ZHFGeUhrVzcvT0t6VFNmYkc0SDIETXJZOUhab1I4ZVgxTHU=

14 Q. Guo, L. Lin, W. He, H. Cai, and K. Hu: Jiangxi Sci. 29 (2011) 410 (in Chinese). https://doi.org/10.13990/ j.issn1001-3679.2011.03.020

15 P. Deng and Z. Li: Water Resour. Power 31 (2013) 14.

16 L. Liu, B. Yan, and B. Xiao: SNWT. Water Sci. Technol. 14 (2016) 43 (in Chinese). https://doi.org/10.13476/j.cnki. nsbdqk.2016.03.008

17 G. Zhao, Y. Han, M. Liu, X. Guo, and S. Cao: J. XYNU (Nat. Sci. Ed.) 30 (2017) 77. https://kns.cnki.net/ $\mathrm{KCMS} /$ detail/detail.aspx dbcode $=$ CJFQ\&dbname $=$ CJFDLAST2017\&filename $=$ XYSK201702015\&v $=$ MjE5NT c3ckpQVFRZWmJHNEg5Yk1yWT1FWVISOGVYMUx1eFITN0RoMVQzcVRyV00xRnJDVVI3cWZidWRx $\mathrm{RnlEbFc}=$

18 J. Wang, J. Guo, and J. Xu: Sci. Geog. Sin. 37 (2017) 611 (in Chinese). https://doi.org/10.13249/j.cnki. sgs.2017.04.015

19 J. Niu, H. Lin, and T. Zhang: Henan Sci. 35 (2017) 1323 (in Chinese). https://kns.cnki.net/KCMS/detail/detail. aspx ?dbcode $=$ CJFQ\&dbname $=$ CJFDLAST2017\&filename $=$ HNKX201708025\&v $=$ MTY5MTZWNzdMTFNQ QWRyRzRIOWJNcDQ5SFIZUjhlWDFMdXhZUzdEaDFUM3FUcldNMUZyQ1VSN3FmYnVkcUZ5SG4=

20 A. Gulakhmadov, X. Chen, N. Gulahmadov, T. Liu, R. Davlyatov, S. Sharofiddinov, and M. Gulakhmadov: Water 12 (2020) 2140. https://doi.org/10.3390/w12082140

21 B. Schaefli, P. Manso, M. Fischer, M. Huss, and D. Farinotti: Renewable Energy 132 (2019) 615. https://doi. org/10.1016/j.renene.2018.07.104

22 W. Buytaert, R. Célleri, B. D. Bièvre, F. Cisneros, G. Wyseure, J. Deckers, and R. Hofstede: Earth Sci. Rev. 79 (2006) 53. https://doi.org/10.1016/J.EARSCIREV.2006.06.002

23 R. L. Hooke: Principles of Glacier Mechanics (Cambridge University Press, UK, 2020) 3rd ed., p. 3.

24 X. Huang, H. Li, and B. Jin: Hydrology (Higher Education Press, Beijing, 1985) 1st ed., p. 1.

25 Y. Jing: J. China Hydrol. 28 (2008) 76 (in Chinese). https://kns.cnki.net/KCMS/detail/detail.aspx?dbcode=CJF $\mathrm{Q} \& d$ bname $=$ CJFD2008\&filename $=$ SWZZ200805021\&v $=$ MDQ0OD11ZHFGeURsVTd2TU5qc1JkTEc0SHRu TXFvOUhaWVI4ZVgxTHV4WVM3RGgxVDNxVHJXTTFGckNVUjdxZmI=

26 P. Walton: Information 6 (2015) 733. https://doi.org/10.3390/info6040733

27 L. T. Pulido: Inf. Int. Interdiscip. J. 11 (2020). https://doi.org/10.3390/INFO11070366

28 Key Technologies for Quantitative Forecast and Control of Huaihe Water Resources: http://www.hrc.gov.cn/ main/kjcghb/197127.jhtml (in Chinese) (accessed 20 January 2020). 